\title{
Stiffness and Strength of Metal Bridge Deck Forms
}

\author{
O. Ozgur Egilmez ${ }^{1}$; Todd A. Helwig ${ }^{2}$; Charles A. Jetann ${ }^{3}$; and Richard Lowery ${ }^{4}$
}

\begin{abstract}
Light gauge metal sheeting is often utilized in the building and bridge industries for concrete formwork. Although the in-plane stiffness and strength of the metal forms are commonly relied upon for stability bracing in buildings, the forms are generally not considered for bracing in steel bridge construction. The primary difference between the forming systems in the two industries is the method of connection between the forms and girders. In bridge construction, an eccentric support angle is incorporated into the connection details to achieve a uniform slab thickness along the girder length. While the eccentric connection is a benefit for slab construction, the flexible connection limits the amount of bracing provided by the forms. This paper presents results from the first phase of a research study investigating the bracing behavior of metal bridge deck forms. Shear diaphragm tests were conducted to determine the shear stiffness and strength of bridge deck forms, and modified connection details were developed that substantially improve the bracing behavior of the forms. The measured stiffness and strength of diaphragms with the modified connection often met or exceeded the values of diaphragms with conventional noneccentric connections. The experimental results for the diaphragms with the modified connection details dramatically improve the potential for bracing of steel bridge girders by metal deck forms.
\end{abstract}

DOI: 10.1061/(ASCE)1084-0702(2007)12:4(429)

CE Database subject headings: Structural stability; Diaphragms; Bridges; Steel; Bracing; Steel decks; Stiffness.

\section{Introduction}

Lateral-torsional buckling during construction is an important design consideration in sizing the cross section of steel girders. Before the fresh concrete cures and composite action between the concrete deck and steel girders is achieved, the steel section supports the entire construction load. During this critical stage, the buckling capacity of the steel girders can be increased by providing bracing either at discrete locations or continuously along the bridge span.

Conventional bracing systems for steel bridge girders consist of cross frames or diaphragms spaced along the bridge length; however, drawbacks to these systems are that they can complicate girder fabrication and erection, thereby leading to increased construction costs. In addition, the brace locations have historically been prone to long-term fatigue problems and can further complicate routine bridge inspections. Therefore, alternative sources of bracing are of interest. A likely bracing source may be the permanent metal deck forms (PMDFs) commonly utilized to support the fresh concrete deck during construction. However, although metal deck forms are often relied upon for lateral bracing in the building industry, the forms are generally not currently considered for bracing in bridges.

\footnotetext{
${ }^{1}$ Assistant Professor, Dept. of Civil Engineering, Izmir Institute of Technology, Izmir, Turkey 35430.

${ }^{2}$ Assistant Professor, Dept. of Civil Architectural and Environmental Engineering, Univ. of Texas at Austin, Austin, TX 78712.

${ }^{3}$ Ph.D. Candidate, Built Environment and Engineering School of Urban Development, Queensland Univ. of Technology, Australia.

${ }^{4}$ Engineer, Kelly Engineering Resources, Houston, Texas.

Note. Discussion open until December 1, 2007. Separate discussions must be submitted for individual papers. To extend the closing date by one month, a written request must be filed with the ASCE Managing Editor. The manuscript for this paper was submitted for review and possible publication on April 13, 2006; approved on July 17, 2006. This paper is part of the Journal of Bridge Engineering, Vol. 12, No. 4, July 1, 2007. CASCE, ISSN 1084-0702/2007/4-429-437/\$25.00.
}

The main difference between the forming systems utilized in the building and bridge industries is the connection details between the girders and the deck forms. In building applications the forms are continuous over the steel beams and typically attach directly to the top flange. In the bridge industry, the forms span between adjacent girders, and the corrugated sheets are fastened to cold-formed angles (support angles) that are attached to the girders, as shown in Fig. 1. The support angle helps the contractor achieve a uniform deck thickness since the form elevation can be adjusted to account for variations in girder camber and flange thickness along the bridge length. The figure shows that the angle may be oriented above or below the flange, depending on the necessary adjustment.

Although the adjustable support angle connection provides some convenience in managing constructability issues, the potential stability bracing provided by the formwork is dramatically reduced since the eccentricities often encountered will substantially reduce the stiffness of a deck form system. As a result, AASHTO specifications (AASHTO 2002, 2004) do not currently permit PMDFs to be considered for bracing in steel bridge girders, primarily due to the softening effect of the eccentric support angles.

This paper documents the results of a research investigation of the bracing behavior of PMDF systems commonly used in the bridge industry. Although the term PMDF (permanent metal deck form) will be used throughout this paper, many engineers may know these forms as stay-in-place (SIP) forms. The purpose of the study was to investigate the bracing behavior of metal deck forms with both existing and improved connection details that increase the stiffness and strength of the deck form systems.

The investigation consisted of experimental and computational studies. Experimental tests were divided into three phases: (1) shear diaphragm tests; (2) full-scale lateral displacement tests on a twin-girder system with PMDFs for bracing; and (3) buckling tests on the twin-girder/PMDF system. This paper presents results from the first phase shear diaphragm tests. A primary aspect of the 


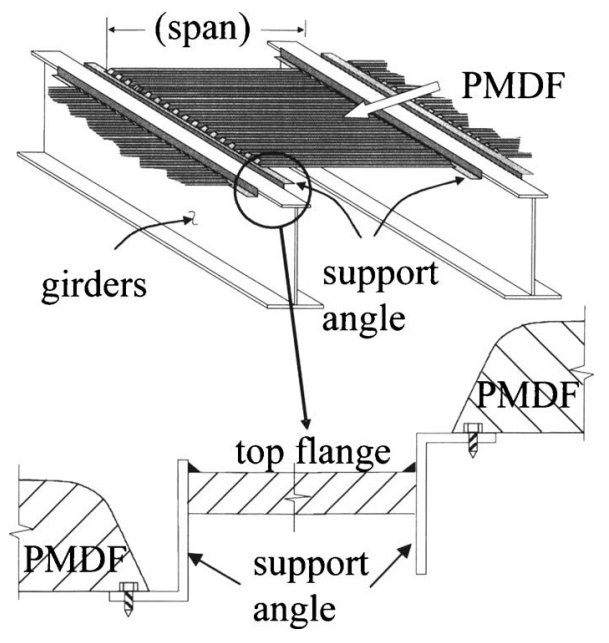

Fig. 1. PMDF connection used in bridge applications

research study was to improve the connection details of PMDF systems to fully utilize the bracing potential of the formwork for bridge applications. Shear diaphragm tests were conducted to determine the shear stiffness and strength of metal bridge deck forms.

Background information is presented in the next section, followed by a description of the shear-panel test frame and laboratory test procedures. Results from the experiments on existing and modified connection details are then compared, followed by a summary of the findings.

\section{Background}

A number of previous investigations have been conducted on shear diaphragm behavior, the most significant of which was perhaps the work conducted at Cornell University in the 1960s and 1970s (Errera and Apparao 1976). A good summary of the current diaphragm design procedures is provided by the Steel Deck Institute (SDI) (Luttrell 2004), and Davies and Bryan (1982) also provide a good summary of diaphragm behavior as well as an overview of numerical modeling techniques for the diaphragms and associated fasteners. Although much of this past work provides a good background on shear diaphragm behavior, the early work generally focused on building applications. The first major study on the in-plane shear response of bridge formwork was conducted at the University of Texas at Austin in the early 1990s (Currah 1993; Soderberg 1994; Helwig 1994). In addition to focusing on the shear behavior of bridge deck forms, the previous study also led to an improved understanding of the stability bracing behavior of shear diaphragms for beams (Helwig and Frank 1999).

Before background material specific to the formwork utilized in the bridge industry is presented, an overview of the properties for stability bracing by shear diaphragms is provided. Fig. 2 depicts the buckling deformations that may take place in a steel girder with metal deck forms fastened to the top flange. The figure shows a plan view of a twin-girder system buckling between cross-frame locations. As the name implies, lateral torsional buckling is a failure mode that includes both lateral and torsional deformations. Bracing can therefore be achieved by restraining either twist of the girder cross section or lateral deformation of the compression flange. Because of the large in-plane shear

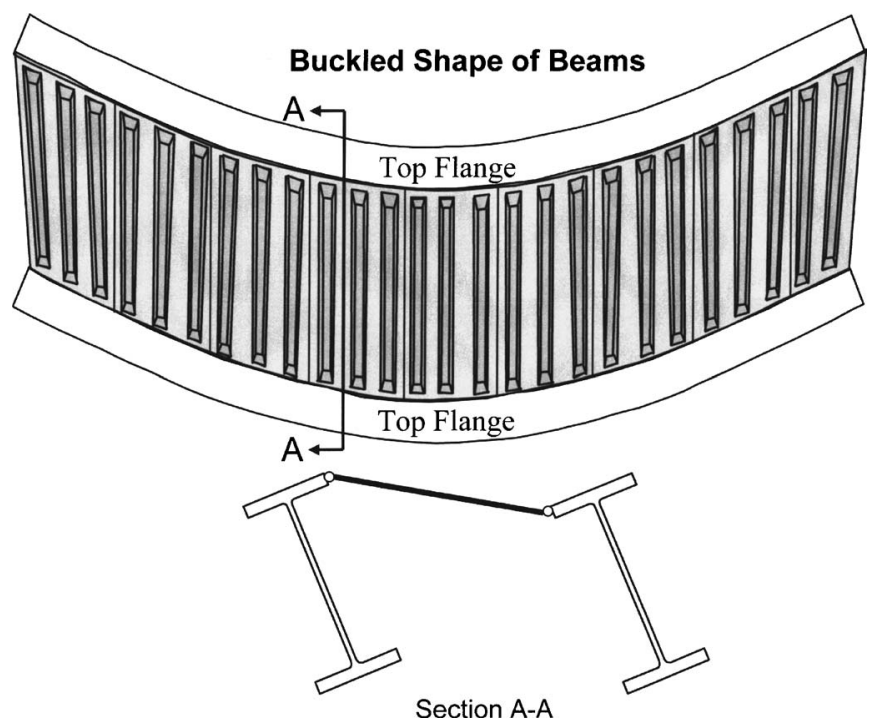

Fig. 2. Buckled shape of beams

strength and stiffness, metal deck forms are often modeled as a diaphragm that restrains the lateral movement of the top flange. The forms near the ends of the beam (or cross-frame locations) will typically be the most effective since the top flange shear deformations are the largest in these regions.

To be effective, stability bracing must satisfy both stiffness and strength requirements (Winter 1958). The shear stiffness and strength characteristics of the forms can be measured experimentally utilizing a cantilever shear test such as the one depicted in Fig. 3. Previous tests on shear panels have shown that the shear modulus of corrugated sheeting is generally not a linear function of the material thickness (Errera and Apparao 1976), and therefore an effective shear modulus, $G^{\prime}$, is utilized that is not a function of the material thickness. Based upon the panel dimensions shown in Fig. 3, the effective shear stiffness is given by

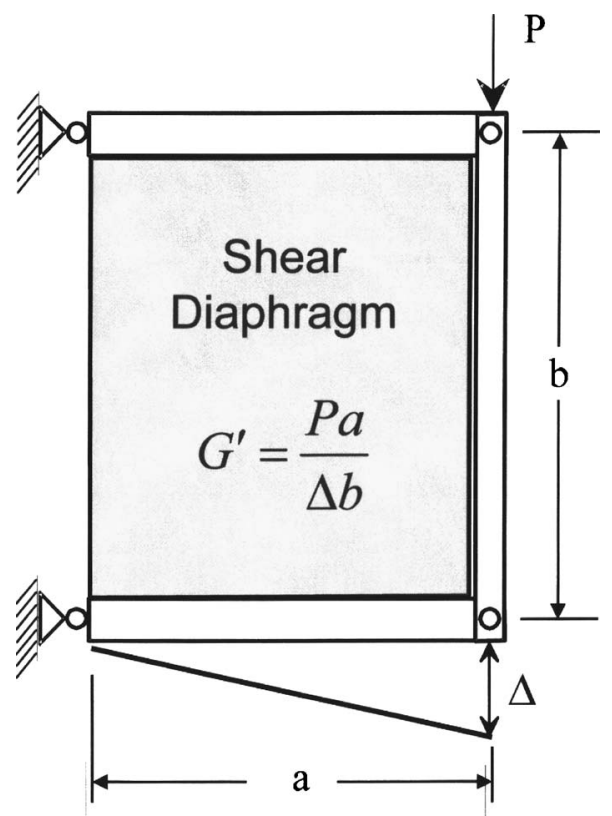

Fig. 3. Cantilever shear frame 


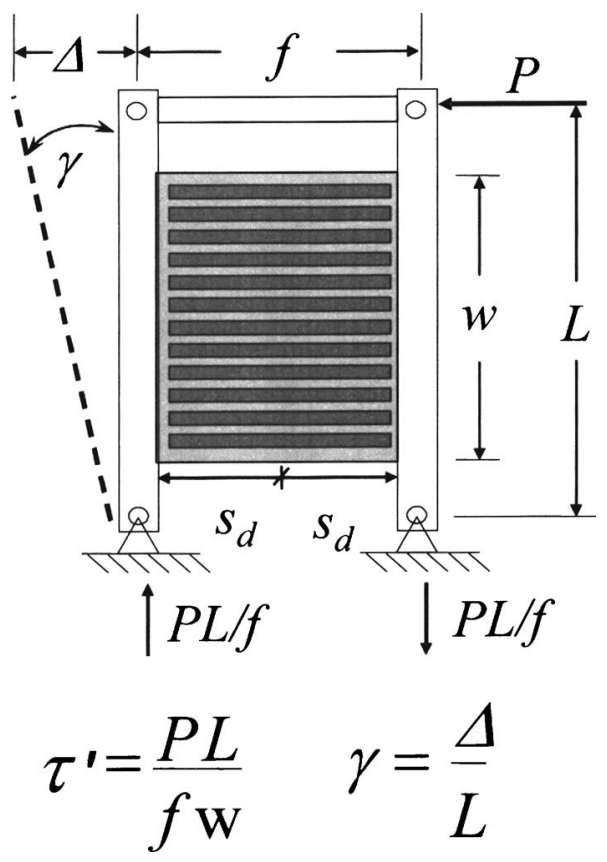

Fig. 4. Cantilever shear frame

$$
G^{\prime}=\frac{\tau^{\prime}}{\gamma}=\frac{(P / b)}{\Delta / a}=\frac{P a}{\Delta b}
$$

Although Eq. (1) represents the effective shear stiffness in a panel, in actual laboratory tests the geometry of the testing frame usually amplifies the applied shear force to the panel. As a result, the testing frame geometry must be considered in evaluating the effective shear stiffness. For example, the testing frame shown in Fig. 4 has distances of $L$ and $f$ between the pinned connections. Although the applied load at the tip of the frame is $P$, the effective shear reaction is $P L / f$ and the effective shear stress is $P L / f w$, where $w=$ width of the panel. The effective shear modulus for such a frame in laboratory measurements would be given by the expression

$$
G^{\prime}=\frac{\tau^{\prime}}{\gamma}=\frac{P L^{2}}{f w \Delta}
$$

For applications in the building industry, in lieu of laboratory testing the effective shear modulus of a diaphragm can be determined using the design tables in the SDI diaphragm design manual (Luttrell 2004). Currah (1993) as well as Egilmez (2005) found reasonable agreement between modified SDI expressions and laboratory test results for the effective shear stiffness and shear strength of bridge decking. Comparisons of the test results with the SDI expressions will be presented in a later paper.

The forms utilized in the bridge industry differ substantially from those used in the building industry in both shape and connection methods. While the forms in the building industry are continuous over the tops of the girders, the metal forms in the bridge industry span between adjacent girders. The ribs of the form corrugations are therefore closed at the ends of the sheets, which increases the stiffness of the forms. However, though the actual bridge forms may be stiffer than the open-ended forms used in the building industry, the overall system stiffness of the formwork is usually substantially lower due to the difference in the connection methods.

Fig. 1 depicts the cold-formed angle in bridge construction

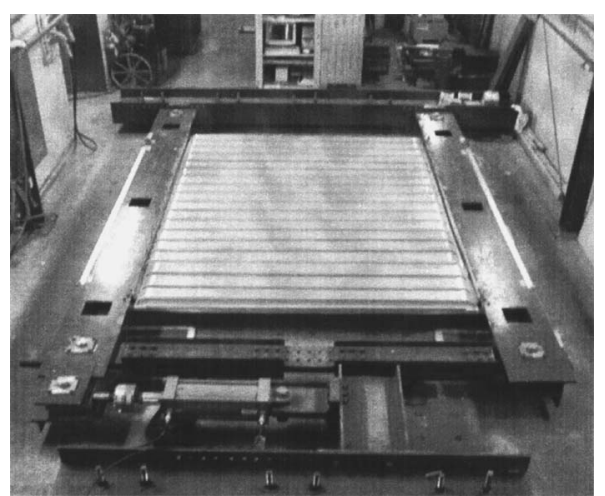

Fig. 5. Test setup for shear tests

that allows the contractor to adjust the form elevation to account for differential camber and flange thickness variations along the girder length. These eccentric support angle connections can severely reduce the stiffness of the PMDF systems. The reason for this large stiffness reduction is because bracing systems are often governed by the equation for springs in series as illustrated in the following expression:

$$
\frac{1}{\beta_{\text {sys }}}=\frac{1}{\beta_{\text {deck }}}+\frac{1}{\beta_{\text {con }}}
$$

where $\beta_{\text {sys }}=$ stiffness of the deck and connection system, $\beta_{\text {deck }}=$ stiffness of the metal deck form, and $\beta_{\text {con }}=$ stiffness of the connection. The system stiffness in Eq. (3) is less than the smaller of either the deck or connection stiffness. Therefore, even though the deck may be very stiff, the flexible connection often leads to a low stiffness in the system. Therefore, a major goal of the research study was to improve the stiffness of the connection.

\section{Laboratory Setup and Testing Procedures}

The research reported in this paper was conducted at the University of Houston. The frame constructed for the diaphragm tests was designed so that a wide range of deck systems with a variety of panel widths and deck spans could be tested. Fig. 5 shows the testing frame, which is very similar to the frame previously depicted in Fig. 4. The two beams running in the vertical direction simulate the top flanges of adjacent girders. These beams consisted of W310 $\times 79$ (US: W $12 \times 53$ ) sections with a 455 $\times 25.3 \mathrm{~mm}(18 \times 1 \mathrm{in}$. $)$ cover plate welded to form a box section, as shown in Fig. 6.

The orientation of the wide flange section and the cover plate provided a large stiffness in the plane of the sheeting. In addition, the box shape of the wide flange and cover plate provided a very large torsional stiffness in the beams, thereby producing a stiff testing frame. The two beams were linked together at the end by an adjustable strap that consisted of a $63 \mathrm{~mm}(2.5 \mathrm{in}$.) thick plate sandwiched between two channels. Internal friction in the testing

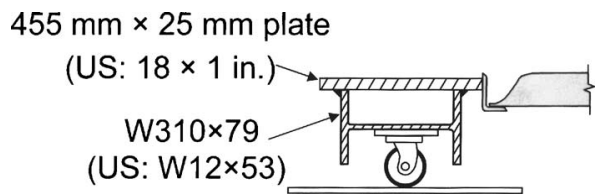

Fig. 6. Cross section of beams from shear frame 
frame was minimized by utilizing needle bearings at the corner connections, and the beams and the strap of the testing frame were supported on metal casters that rolled on polished steel plates that were leveled and supported on grout.

To facilitate assembly, the three casters along each beam were offset along the longitudinal axis of the beam so the member was stable under its own weight. Although the total frame (beams and strap) weighed nearly $2,270 \mathrm{~kg}(5,000 \mathrm{lb})$, friction tests were conducted and showed that static forces in the range of $14-28 \mathrm{~kg}$ (30-60 lb) were required to displace the frame. The range in the forces was most likely due to slight misalignments in the swivel casters that supported the testing frame.

The forces required to move the frame in the friction tests were measured with a spring scale accurate to $0.23 \mathrm{~kg}(0.5 \mathrm{lb})$. This relatively small magnitude of load was considered negligible for the ultimate load levels applied to the frame. In addition, because the friction was generally constant over the range of motion of the frame, there was no measurable effect on the slope of the shear stress versus strain curve, and therefore measurements of $G^{\prime}$ were unaffected. A load cell with a $445 \mathrm{kN}$ (100 kip) capacity monitored the force in a hydraulic actuator that was used to displace the tip of the frame. The shear strains were obtained using linear potentiometers that measured the movements of the beams of the shear frame.

Once each deck panel was assembled into the frame, three separate phases of loading were conducted. In the first two phases of loading, the panel was subjected to cyclic loading (in both directions) within the linear-elastic range. During the first phase of loading, the panel had no applied gravity load, and during the second phase, steel plates (SI: $610 \mathrm{~mm} \times 1,220 \mathrm{~mm} \times 50.6 \mathrm{~mm}$, US: $2 \mathrm{ft} \times 4 \mathrm{ft} \times 2 \mathrm{in}$.) were used to simulate the weight of fresh concrete on the forms.

The plates were utilized to measure the effects of friction between the contact surfaces of the PMDF system that would normally be caused by fresh concrete. The number of plates generally simulated approximately $80 \mathrm{~mm}$ (3.1 in.) of concrete on the forms. While this is significantly lower than the weight of a 200-250 $\mathrm{mm}(8-10$ in.) slab that might normally be employed in bridge construction, the weight of the plates was large enough to indicate the effect of internal friction between the form sheets on the shear stiffness.

After determining the effective stiffness of the panels within the elastic range, the panel was finally loaded to failure in one direction. During the elastic load phases, the effective stiffness of the panel was determined with and without the superimposed gravity load using a linear regression on the test data. During the ultimate loading phase, two values of the effective stiffness were determined using the secant stiffness at 40 and $80 \%$ of the ultimate load. Although the SDI manual (Luttrell 2004) recommends the secant stiffness at $40 \%$ of the ultimate load, the stiffness at $80 \%$ of the ultimate load provides an indication of the degradation in the stiffness with increasing load.

The deck panel specimens tested during this phase of the study were preclosed (tapered closure) as depicted in Fig. 7. PMDF spans of 2,410 and 2,720 mm (95 and $107 \mathrm{in}$.) were considered that will henceforth be referred to as 2.4 and $2.7 \mathrm{~m}(8$ and $9 \mathrm{ft})$, respectively. These spans are representative of the PMDF spans frequently employed in steel girder construction. The figure also shows the dimensions of a typical profile of a PMDF sheet. Sheet thicknesses of $0.75,0.91,1.22$, and $1.63 \mathrm{~mm}(0.030,0.036,0.048$, and $0.060 \mathrm{in}$.) were tested in the study. Much of the discussion will focus on the results with the $1.22 \mathrm{~mm}$ (0.048 in.) deck, however, there was generally not a significant difference in the results
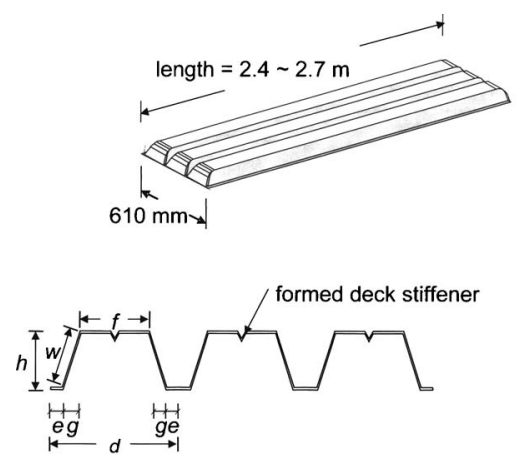

$h=$ depth of corrugation $=75 \mathrm{~mm}$

$e=$ bottom flange of corrugation $=25 \mathrm{~mm}$

$f=$ top flange of corrugation $=140 \mathrm{~mm}$

$d=$ pitch of corrugation $=203 \mathrm{~mm}$

$w=$ web of corrugation $=77 \mathrm{~mm}$

$g=$ projection of web of corrugation $=6.5 \mathrm{~mm}$

$s=$ developed width of corrugation $=2 e+2 w+f=343 \mathrm{~mm}$

Fig. 7. PMDF profile and dimensions

with the other material thicknesseses are tabulated in the Appendix.

Deck form sheets spanned between the beams of the test frame and were supported on cold-formed, L $76 \times 51 \times 3.5$ (US: L3 $\times 2$ $\times 0.138)$ galvanized angles, which are typical of those used in bridge construction. The support angles were welded directly to the top plate of the shear test frame loading beams using the conventional connection method, which consists of $3 \mathrm{~mm}$ fillet welds $37.5 \mathrm{~mm}$ long, intermittently spaced $300 \mathrm{~mm}$ on center ( 0.125 in. welds, 1.5 in. long, spaced 12 in. on center). At the ends of the individual support angles, $76 \mathrm{~mm}$ (3 in.) long fillet welds were used.

The forms were fastened to the support angles in every trough by $19 \mathrm{~mm}$ long, $6.4 \mathrm{~mm}$ diameter TEKS screws (0.75 in. long, 0.25 in. diameter). TEKS screws were also used to fasten adjacent sheets along side-laps with a maximum $460 \mathrm{~mm}$ (18 in.), centerto-center spacing between fasteners as stated by Texas Department of Transportation (TxDOT) PMDF standards TxDOT (2004). In addition, special attention was paid to ensure that the TxDOT PMDF standards were followed in regard to maintaining the minimum $12.5 \mathrm{~mm}$ (0.5 in.) fastener edge distance on forms and support angles, as depicted in Fig. 8.

Tests were conducted with a variety of support details for the cold-formed support angles. Initial tests were conducted using conventional connection details for the support angles with and without eccentricities. For tests without eccentricity, the long leg of the support angle was oriented vertically down, and the short

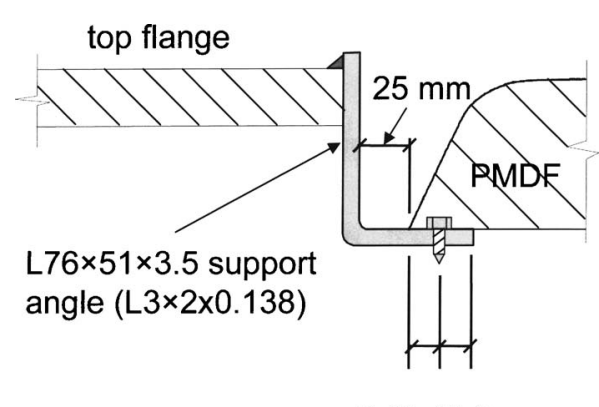

$2 @ 12.5 \mathrm{~mm}$

Fig. 8. Support angle-PMDF connection 


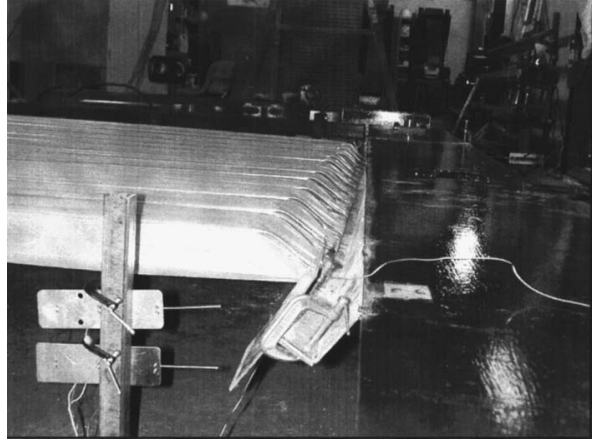

Fig. 9. Failure of eccentric support angle

leg was placed flush with the level of the top flange plate. For tests with maximum eccentricity, the long leg of the support angle was oriented vertically upward with its edge extending $3 \mathrm{~mm}$ (0.125 in.) above the top flange plate of the support beam, resulting in an eccentricity of $73 \mathrm{~mm}$ (2.88 in). This was the maximum eccentricity that could be achieved while still maintaining enough overlap for welding. Although in actual construction the eccentricity typically varies between 0 and $73 \mathrm{~mm}$ ( 0 and $2.88 \mathrm{in}$.), the extreme eccentricities that were tested represent the best and worst scenarios that might be encountered in practice.

The failure of the deck panel for cases with maximum eccentricity typically involves a severe deformation of the support angle at the corners of the panel as demonstrated by the photo in Fig. 9. While a number of modified connection details were tested to control the angle deformation, one proved to be both practical and effective. This proposed modification involves an angle (the same size as the support angle) that spans between adjacent girder flanges, as shown in Fig. 10. These angles will be referred to as stiffening angles in the remainder of the paper.

The stiffening angles were positioned to coincide with a sidelap seam so the deck could be screwed directly to the angle along the length. The spacing between the stiffening angles varied between 2.4 and $4.8 \mathrm{~m}$ ( 8 and $16 \mathrm{ft}$ ) in the shear tests. A wider spacing of the support angles was investigated in the second and third phases of the study, but the spacing in the first phase was limited by the test frame width. To position the stiffening angle at the same eccentricity as the support angle, the ends of the stiffening angle were welded to the stems of fabricated T-sections that were bolted to the underside of the top flange plate, as shown in Fig. 11.

The $16 \mathrm{~mm}$ diameter (0.625 in.) bolts were offset by approximately $25 \mathrm{~mm}$ (1 in.) to provide some moment restraint to the T-sections, which were fabricated by two pieces of the support angle material (SI: L76 $\times 51 \times 3.3$; US: L3 $\times 2-0.138$ in.) with

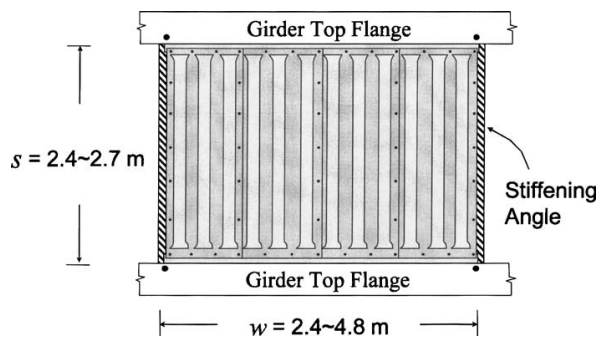

Fig. 10. Stiffening angle to control support angle deformation

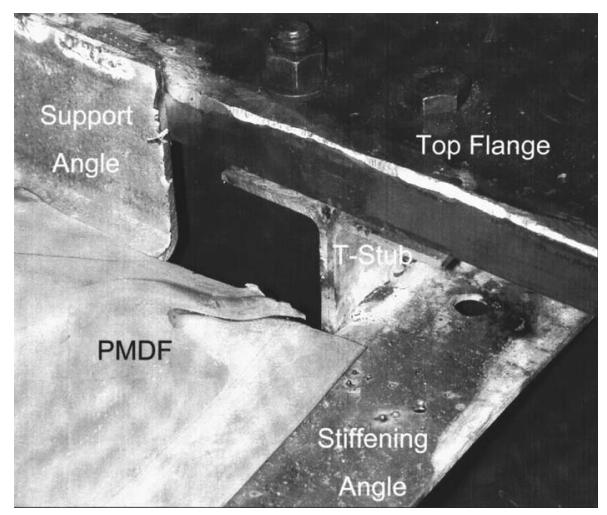

Fig. 11. Stiffening angle eccentric connection detail

the long legs back to back. A variety of prefabricated sections (hot rolled or cold formed) could also be used for this purpose. In most field applications these sections would be welded to the top flange. The T-sections or other connection plates could also be shop welded since there is some flexibility in the location of the stiffening angle to deck connections.

The parameters that were investigated included panel width and length, metal deck thickness, stiffener spacing, and support angle eccentricity. Tests were conducted with a variety of support configurations, as shown in Fig. 12: (1) no eccentricityunstiffened; (2) no eccentricity-stiffened; (3) maximum eccentricity-unstiffened; and (4) maximum eccentricity-stiffened. The stiffening angle location/eccentricity is indicated by the vertical position of the $\mathrm{X}$.

\section{Test Results}

Twenty PMDF shear panels were tested in the investigation. Although gravity loading was simulated with the steel plates discussed in the last section, the primary loading was applied in the

\section{Non-Eccentric Connections}
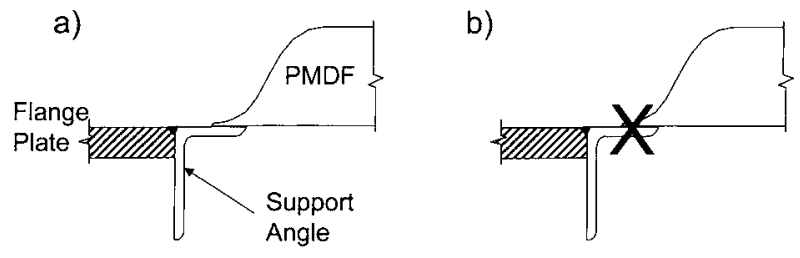

\section{Eccentric Connections}

c)

d)
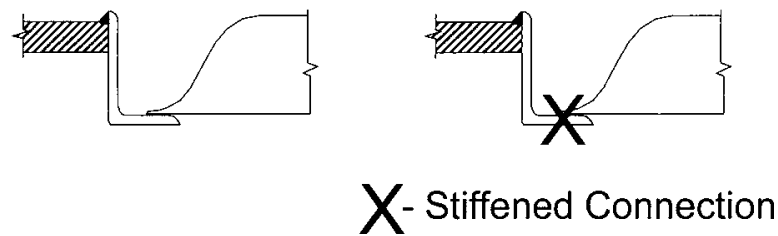

Fig. 12. Connection detail symbol illustration 


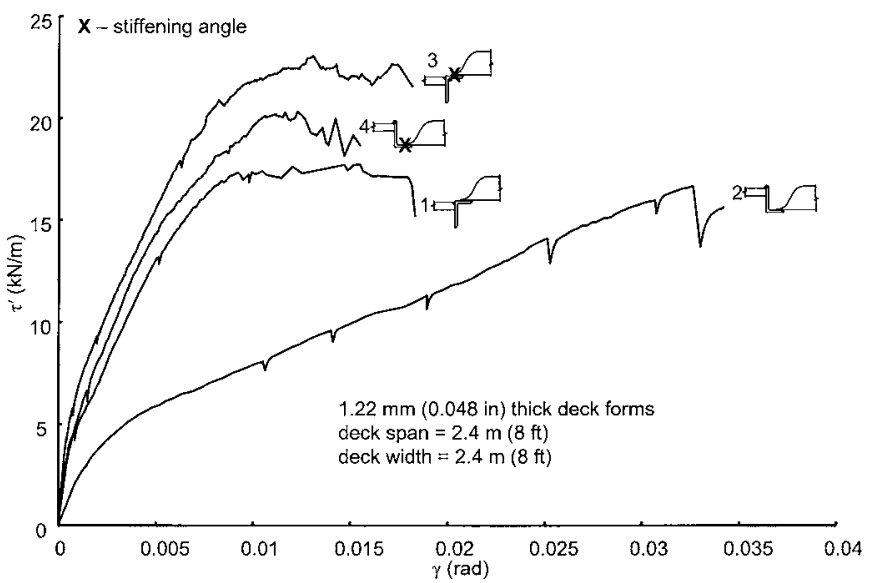

Fig. 13. Effect of connection details on PMDF behavior

plane of the decking using a hydraulic actuator. Each panel was subjected to cyclic in-plane loading within the linear load range, with and without the applied gravity loading. Finally, the panels were loaded to in-plane shear failure. Shear tests were conducted on decking with a thickness of $0.75,0.91,1.22$, and $1.63 \mathrm{~mm}$ $(0.030,0.036,0.048$, and 0.060 in.). Since the behavior of the PMDF systems with these four different metal thicknesses was very similar in each case, much of the discussion will focus on the $1.22 \mathrm{~mm}$ (0.048 in.) thick deck systems.

Although shear tests with no superimposed gravity load were also conducted, for brevity only the results for tests with the simulated concrete loading will be discussed. In general, there was approximately a $10 \%$ increase in the system shear stiffness due to the friction caused between the overlapping PMDF surfaces by the superimposed gravity load. From a buckling perspective, a large portion of the applied girder load comes from the weight of the fresh concrete on the forms, and therefore the results with the simulated concrete gravity load are more practical than those without the superimposed gravity load.

A discussion of the existing connection details was presented in the last section. The failure mode of PMDF panels with the existing connection detail and maximum eccentricity was shown in Fig. 9, in which the support angle experienced excessive rotation. The effect of connection eccentricity on the stiffness is shown in Fig. 13, which presents a graph of the effective shear stress, $\tau^{\prime}$, versus the shear strain, $\gamma$, for four different tests on a deck with $1.22 \mathrm{~mm}$ thickness (0.048 in.). A shear panel $2.44 \mathrm{~m}$ $\times 2.44 \mathrm{~m}(8 \mathrm{ft} \times 8 \mathrm{ft})$ was used in the tests.

The two curves labeled Tests 1 and 2 represent the behavior of the existing connection details, and the small figure labeling each curve depicts the connection eccentricity employed in each test. Test 1 had no eccentricity, while Test 2 had the maximum eccentricity of nearly $76 \mathrm{~mm}$ (3 in.). The large eccentricity dramatically reduces the stiffness of the PMDF system, as evidenced by the much smaller slope of the curve of $\tau^{\prime}$ versus $\gamma$.

The beneficial effects of the stiffening angles on the shear stiffness and strength are shown by the curves labeled Test 3 and Test 4, which graph the respective results for no-eccentricity and maximum eccentricity. In both cases the stiffening angles were positioned at the ends of the $2.44 \mathrm{~m}(8 \mathrm{ft})$ square panels. Test 3 had no eccentricity, and the stiffness and strength are higher than in the corresponding noneccentric case without the stiffening angles (Test 1). The effect of the eccentricity on the stiffness is significantly less for the panels with the stiffening angles. A com-

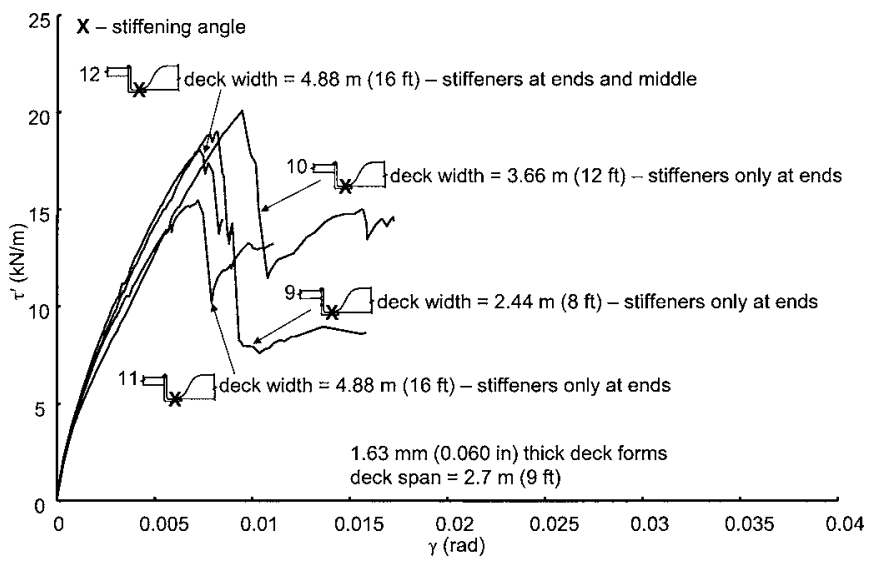

Fig. 14. Stress versus strain for $1.63 \mathrm{~mm}$ (16 gauge) PMDF

parison of the results for Tests 1 and 4 shows that despite the large difference in the eccentric end connections, the panels with the stiffening angles had a higher stiffness and strength than the existing connection detail with no eccentricity.

While Fig. 9 indicates that the failure of the existing eccentric connection detail typically occurs due to excessive angle rotation, the failure of the modified connection details varied depending on the panels. In the cases of thinner decks, the failure often occurred due to bearing failures in the deck material around the fasteners. The bearing deformation was the largest around fasteners near the corner of the panel, and the final failure in these cases often consisted of end tear-out around the corner fasteners. Although the failure of all four tests on the $1.22 \mathrm{~mm}(0.048 \mathrm{in}$.) thick deck shown in Fig. 13 was due to excessive bearing deformation and end tear-out, for cases with wider panels, the $1.22 \mathrm{~mm}$ (0.048 in.) deck also failed by shearing of a corner fastener. Results from the wider panels will be discussed later in this section.

The failure mode for all of the $1.63 \mathrm{~mm}$ (0.060 in.) deck was shearing of fasteners in the corner of the panel. The effective stress versus shear strain curves for these tests are shown in Fig. 14. The failures in these cases were relatively sudden, resulting in a sudden drop in the stress-strain curves, as shown in the graphs. Since there was very little bearing deformation around the fasteners in these cases, the corner fasteners had the highest shear forces. Bearing deformations in the sheeting tend to engage more fasteners, resulting in more ductile behavior and in some cases higher strengths. This can be seen by comparing the ultimate strengths of the curves shown in Figs. 13 and 14. Although the $1.63 \mathrm{~mm}$ (0.060 in.) deck would be expected to have a higher

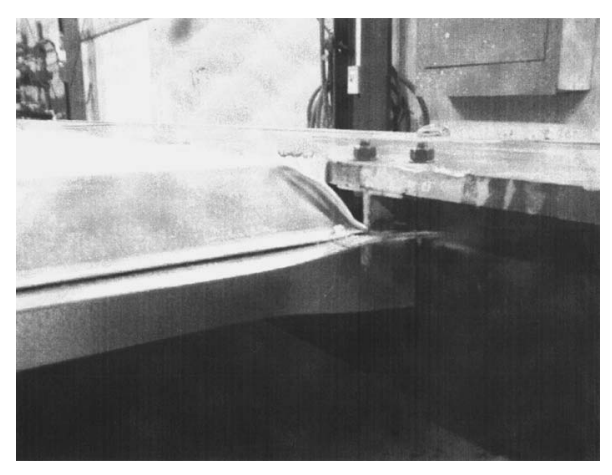

Fig. 15. Buckling of stiffening angle at failure 
Table 1. Shear Test Results for $1.22 \mathrm{~mm}$ (0.048 in.) Thick PMDF Specimens

\begin{tabular}{|c|c|c|c|c|c|c|c|c|}
\hline $\begin{array}{l}\text { Connection } \\
\text { Type }\end{array}$ & $\begin{array}{c}\text { Test \# and } \\
\text { Detail }\end{array}$ & $\begin{array}{c}\text { b) } \\
\text { Span (m) }\end{array}$ & $\begin{array}{c}\text { c) } \\
\text { Width (m) }\end{array}$ & $\begin{array}{c}\text { d) } \\
\text { Stiffener } \\
\text { spacing } \\
\text { (m) }\end{array}$ & $\begin{array}{c}\text { e) } \\
S_{u l t} \\
(\mathrm{kN} / \mathrm{m})\end{array}$ & $\begin{array}{c}\text { f) } \\
G_{0}^{\prime} \\
(\mathrm{kN} / \mathrm{m}-\mathrm{rad})\end{array}$ & $\begin{array}{c}\text { g) } \\
\text { G }_{0.4}^{\prime} \\
\left(\% G_{0}^{\prime}\right) \\
(\mathrm{kN} / \mathrm{m}-\mathrm{rad})\end{array}$ & $\begin{array}{c}\mathrm{h}) \\
G_{0.8}^{\prime} \\
\left(\% G_{0}^{\prime}\right) \\
(\mathrm{kN} / \mathrm{m}-\mathrm{rad})\end{array}$ \\
\hline I. Unstiffened & 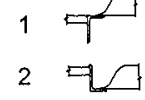 & $\begin{array}{l}2.44 \\
2.44\end{array}$ & $\begin{array}{l}2.44 \\
2.44\end{array}$ & - & $\begin{array}{l}17.7 \\
16.6\end{array}$ & $\begin{array}{l}6376 \\
2195\end{array}$ & $\begin{array}{r}3358(53 \%) \\
952(43 \%)\end{array}$ & $\begin{array}{r}2437(38 \%) \\
562(26 \%)\end{array}$ \\
\hline II. Stiffened & $\begin{array}{l}3 \\
4 \\
5\end{array}$ & $\begin{array}{l}2.44 \\
2.44 \\
2.74\end{array}$ & $\begin{array}{l}2.44 \\
2.44 \\
2.44\end{array}$ & $\begin{array}{l}2.44 \\
2.44 \\
2.44\end{array}$ & $\begin{array}{r}23.1 \\
20.3 \\
19.1\end{array}$ & $\begin{array}{r}10520 \\
7295 \\
6530\end{array}$ & $\begin{array}{l}4586(44 \%) \\
3933(54 \%) \\
3550(54 \%)\end{array}$ & $\begin{array}{l}2791(27 \%) \\
2489(34 \%) \\
2622(40 \%)\end{array}$ \\
\hline
\end{tabular}

strength than the $1.22 \mathrm{~mm}$ (0.048 in.) decks, Figs. 13 and 14 show that the thicker deck had lower strengths due to shearing of the fasteners. As will be shown later in this section, for wider panels even the $1.22 \mathrm{~mm}$ (0.048 in.) deck sometimes failed by shearing of corner fasteners, resulting in a slightly lower strength.

In some cases with the thicker decks, failure occurred in the deck stiffening angle, as shown in Fig. 15, in which the stiffening angle has buckled. The buckling deformation can be seen in the leg of the stiffening angle that is pointing downward. Using a thicker angle would increase the capacity of the support angle; however, the capacity would more than likely then be controlled either by shearing a TEK screw or by a bearing failure in the deck material around a fastener at load levels very close to the failure shown in Fig. 15. The failure of the system with the stiffened connection is significantly different than the large angle rotation for the conventional connection detail shown previously in Fig. 9. For systems with the stiffening angle, rotation of the support angle was generally insignificant at failure.

With regard to the shear panel bearing failures, all of the tests conducted in the first phase of the testing (shear frame tests) employed the conventional geometric layout of the bridge decking. The conventional geometric layout uses the L $76 \times 51 \times 3.5$ (US: L3 $\times 2 \times 0.138$ ) support angles with a detail shown earlier in Fig. 8. With the L $76 \times 51 \times 3.5$ (US: L $3 \times 2 \times 0.138$ ) support angle, the prescribed overlap between the decking and the outstanding angle leg was $254 \mathrm{~mm}$ (1 in.), which produces an edge distance for the fasteners of $127 \mathrm{~mm}$ ( $0.5 \mathrm{in}$.). However, due to imperfections in the girders and the decking, the edge distance can be substantially less than $127 \mathrm{~mm}(0.5 \mathrm{in}$.). Later in the study (Egilmez 2005), the recommended support angle size was changed from $\mathrm{L} 76 \times 51 \times 3.5$ (US: $\mathrm{L} 3 \times 2 \times 0.138$ ) to $\mathrm{L} 76 \times 76$ $\times 3.5$ (US: $\mathrm{L} 3 \times 3 \times 0.138$ ). Using an angle with the longer support leg significantly improved the bearing capacity since it enabled the fastening screws to be installed with larger edge distances.

Although ductility in the thicker decks is not a desirable characteristic, the lack of ductility does not generally create a major problem for the forms with regard to providing stability bracing. Stability bracing systems are generally designed to remain well in the elastic range. In addition, the large stiffness of the thicker decks will help to minimize the stability induced brace forces. Past studies (Galambos 1998) on stability-induced forces have shown that the forces are a direct function of the stiffness provided. A stiffer brace will result in lower fastener forces, and therefore the lack of ductility will be accounted for in the design methodology.

The findings for the $1.22 \mathrm{~mm}$ (0.048 in.) decking are summarized in Table 1, which has been divided into eight columns labeled (a) through (h). Column (a) shows the test number and a pictorial illustration of the connection detail that was used. Columns (b) through (d) present the panel geometry, which consists of the span of the deck, the width of the shear panel, and the spacing between the stiffening angles. Columns (e) through (h) list the measured data from each test. Column (e) lists the effective shear strength of the panel $\left(S_{\text {ult }}\right)$, while the last three columns pertain to the shear stiffness of the panel.

The initial "elastic effective shear modulus," $G_{0}^{\prime}=$ initial stiffness of the diaphragm with superimposed dead load from the elastic cycling loading and is given in column (f). For design, the Steel Deck Institute recommends use of the secant stiffness at a load level of $40 \%$ of the ultimate capacity, $G_{0.4}^{\prime}$ (Luttrell 1981). The value of $G_{0.4}^{\prime}$ is listed in column $(\mathrm{g})$. The value given in parentheses is the ratio of $G_{0.4}^{\prime} / G_{0}^{\prime}$ and indicates the reduction in stiffness over the first $40 \%$ of the ultimate loading. Although the SDI manual recommends use of $40 \%$ of the ultimate load in calculating the secant stiffness, a similar secant stiffness at $80 \%$ of the ultimate load can indicate how well the diaphragm maintains its stiffness. Therefore, the last column provides the value $G_{0.8}^{\prime}$ as well as the stiffness ratio $G_{0.8}^{\prime} / G_{0}^{\prime}$.

The tests have been divided into three categories (I: unstiffened; II: stiffened; and III: stiffened), based upon testing parameters and comparison of results. The Category I results demonstrate the performance of the conventional connection details, which are unstiffened, Category II the effect of connection eccentricity and deck span on stiffened connections, and Category III the effects of the panel aspect ratio and stiffener angle spacing. The aspect ratios (deck span to panel width) of the tests shown in categories I and II were 1.0, with the exception of Test 5, which was slightly greater than 1.0 since the deck span was approximately $12 \%$ longer than the other decks tested.

The results tabulated for the Category I tests with the conventional details provide numerical indicators for the trends of the results graphed earlier in Fig. 13. While the difference in the 
ultimate strength of the panels with the eccentric and noneccentric connection details is not large, the difference in the stiffnesses. The Category I results in column $(\mathrm{g})$ show that the deck panel with zero eccentricity was approximately three times stiffer than for the test with the maximum eccentricity.

For the systems with stiffening angles, the support angle eccentricity did not have as large an impact on the system stiffness, as demonstrated by comparing the shear stiffness given in column (g) for Tests 3 and 4 . The test with zero eccentricity is only about $17 \%$ stiffer than the system with the maximum eccentricity. As shown in Fig. 13, the stiffness and strengths of the stiffened systems were higher than the corresponding values for the decks with conventional connection details and no eccentricity.

Most of the forming systems used in bridge deck systems have

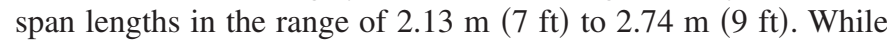
in some cases a shorter or wider girder spacing may be employed, most clear girder spacings fall in this range. The range of deck spans tested experimentally consisted of either $2.44 \mathrm{~m}(8 \mathrm{ft})$ or $2.74 \mathrm{~m}(9 \mathrm{ft})$ decks. Comparison of columns (e) and $(\mathrm{g})$ for Tests 4 and 5 shows that the deck span had a small effect on the performance of the deck forms, where the strength and stiffness of the deck panel decreased by approximately $10 \%$. In general, however, the differences in the panel performance based upon the span of the PMDF were relatively small.

The tests presented in Category III reflect the impact of the panel width and stiffener angle spacing on the behavior. In Tests 6 and 7, the panel width was increased to 3.66 and $4.88 \mathrm{~m}$ (12 and $16 \mathrm{ft}$ ), respectively. In both cases the stiffening angles were only present at the outside edges of the panel. Comparing the stiffness and strength of the panels between Tests 6 and 7 relative to Test 5, the stiffness (column g) was increased by $8 \%$ for Test 6 and reduced by $4 \%$ for Test 7 , while the strength (column e) was reduced by approximately 6 and $15 \%$ for 3.66 and $4.88 \mathrm{~m} \mathrm{(12} \mathrm{and}$ $16 \mathrm{ft}$ ) wide panels, respectively.

The strengths of the PMDF systems with the wider panels were controlled by shearing a fastener at the corner of the panels.
While the failures of the wider panels of the $1.22 \mathrm{~mm}(0.048 \mathrm{in}$.) were not as abrupt as those observed for the $1.63 \mathrm{~mm}$ (0.060 in.) deck panels, as shown in Fig. 14, the failures were not as ductile as those observed with the $2.44 \mathrm{~m}(8 \mathrm{ft})$ wide $1.22 \mathrm{~mm}$ (0.048 in.) thick panels. While the values of $S_{\text {ult }}$ were smaller for the wider panels, the smaller value of $S_{\text {ult }}$ should not be confused with a lower overall load level. The absolute load levels resisted by the panel were higher with the 3.66 and $4.88 \mathrm{~m}$ (12 and $16 \mathrm{ft})$ wide panels compared to the $2.44 \mathrm{~m}(8 \mathrm{ft})$ wide panels, but the force per unit length was slightly smaller with the wider panels.

Test 8 used the wider panel width of $4.88 \mathrm{~m}(16 \mathrm{ft})$, but the spacing between the stiffening angles was $2.44 \mathrm{~m}(8 \mathrm{ft})$. Therefore there were three stiffening angles in the panel: two at the outside edges and one in the middle. The ultimate effective shear strength (column e) of the panel increased slightly relative to the Test 7 results. In analyzing the stiffness performance of the Test 8 panel, the measured stiffness at 40 and $80 \%$ of the ultimate load was smaller than the results observed in Tests 6 and 7. It is not clear why the measured stiffness was lower for Test 8 .

The PMDF systems with other metal thicknesses exhibited similar behavior similar to that observed for the $1.22 \mathrm{~mm}$ (0.048 in.) deck. Results from the tests on these other panels are presented in Table 2.

\section{Summary and Conclusions}

This paper presents results from the first phase of laboratory tests in a research investigation targeted at improving the bracing potential of PMDF systems used in the bridge industry. Stabilitybracing systems for steel bridges typically consist of cross-frames spaced along the bridge length. Although metal deck forms are often used to support fresh concrete during construction, the forms are not currently permitted for use in bracing because of the relatively flexible connections with which the forms are fastened

Table 2. Shear Test Results for $0.75,0.91$, and $1.63 \mathrm{~mm}$ ( 0.030 in, 0.036 in, and 0.060 in) Thick PMDF

\begin{tabular}{|c|c|c|c|c|c|c|c|c|}
\hline $\begin{array}{l}\text { Connection Type } \\
\text { and Metal } \\
\text { Thickness }\end{array}$ & $\begin{array}{c}\text { Test \# and } \\
\text { Detail }\end{array}$ & $\begin{array}{c}\text { b) } \\
\text { Span }(m)\end{array}$ & $\begin{array}{c}\text { c) } \\
\text { Width }(m)\end{array}$ & $\begin{array}{c}\text { d) } \\
\text { Stiffener } \\
\text { spacing } \\
(m)\end{array}$ & $\begin{array}{c}\text { e) } \\
S_{u l t}^{\prime} \\
(\mathrm{kN} / \mathrm{m})\end{array}$ & $\begin{array}{c}f) \\
G_{0}^{\prime} \\
(\mathrm{kN} / \mathrm{m}-\mathrm{rad})\end{array}$ & $\begin{array}{c}\mathrm{g}) \\
G_{0.4}^{\prime} \\
\left(\% G_{0}^{\prime}\right) \\
(\mathrm{kN} / \mathrm{m}-\mathrm{rad})\end{array}$ & $\begin{array}{c}\text { h) } \\
G_{0.8}^{\prime} \\
\left(\% G_{0}^{\prime}\right) \\
(\mathrm{kN} / \mathrm{m}-\mathrm{rad})\end{array}$ \\
\hline I. Unstiffened & $9 \sqrt{\square}$ & 2.44 & 2.44 & - & 10.8 & 2365 & $1543(65 \%)$ & $1415(60 \%)$ \\
\hline $0.75 \mathrm{~mm}$ (22 gage) & $10 \curvearrowleft \frown$ & 2.44 & 2.44 & - & 6.7 & 733 & $666(91 \%)$ & $557(33 \%)$ \\
\hline I. Unstiffened & $11 \square$ & 2.44 & 2.44 & - & 13.1 & 5102 & $2151(42 \%)$ & $1670(33 \%)$ \\
\hline $0.91 \mathrm{~mm}$ (20 gage) & $124 \backsim$ & 2.44 & 2.44 & - & 10.3 & 1679 & $1012(62 \%)$ & $484(66 \%)$ \\
\hline II. Stiffened & $13 \square^{*}$ & 2.44 & 2.44 & 2.44 & 13.7 & 2962 & $2545(86 \%)$ & $2070(70 \%)$ \\
\hline $0.75 \mathrm{~mm}$ (22 gage) & 14 ๑ & 2.44 & 2.44 & 2.44 & 12.6 & 2244 & $1715(76 \%)$ & $1596(71 \%)$ \\
\hline II. Stiffened & $150^{*}$ & 2.44 & 2.44 & 2.44 & 15.6 & 6954 & $4607(66 \%)$ & $2712(39 \%)$ \\
\hline $0.91 \mathrm{~mm}$ (20 gage) & 16 ฯ & 2.44 & 2.44 & 2.44 & 13.7 & 4198 & $2580(61 \%)$ & $2017(48 \%)$ \\
\hline III. Stiffened & 15 & 2.74 & 2.44 & 2.44 & 19.0 & 6381 & $3672(58 \%)$ & $2697(42 \%)$ \\
\hline \multirow[t]{3}{*}{$1.63 \mathrm{~mm}$ ( 16 gage) } & 16 与 & 2.74 & 3.66 & 3.66 & 20.1 & 6054 & $2963(49 \%)$ & $2386(39 \%)$ \\
\hline & 15 & 2.74 & 4.88 & 4.88 & 15.5 & 6486 & $3927(61 \%)$ & $2673(41 \%)$ \\
\hline & $16 \square *$ & 2.74 & 4.88 & 2.44 & 18.1 & 7959 & $4020(51 \%)$ & $2938(37 \%)$ \\
\hline
\end{tabular}


to the steel girders. The current connection methods provide the contractor the ability to adjust the form elevation to account for variations in the girder camber and flange thickness along the girder length.

The results from laboratory tests conducted on PMDF systems in the bridge industry have been presented and demonstrate that a relatively simple modification to currently employed connection details markedly improves the shear strength, shear stiffness, and overall performance of these systems. The modification employs stiffening angles spaced along the length of the bridge to control connection deformations. While dramatically improving the stiffness of the PMDF system, the stiffening angles still permit the contractor the ability to adjust the form elevations.

Laboratory testing was conducted on more than 20 deck form systems with and without modified connection details. With conventional connection details, the eccentric connection can reduce the shear stiffness of the PMDF system by a factor of 3 or more, depending on the thickness of the metal sheeting used. In systems with modified connection details, the spacing between the stiffening angles was varied from 2.4 to $4.8 \mathrm{~m}$ ( 8 to $16 \mathrm{ft}$ ), and the stiffness of the PMDF systems with the stiffening angle and maximum eccentricity $[\sim 70 \mathrm{~mm}(2.75 \mathrm{in})$.$] was higher than the$ stiffness of conventional details with zero eccentricity. The corresponding strength of the diaphragms with the stiffened connections and the maximum eccentricity were also higher than the conventional details with zero eccentricity.

Based upon the shear tests with the modified connection details reported in this paper, permanent metal deck form systems are a viable source of stability bracing that can be used to reduce the number of cross frames required on steel girder bridges. The bracing potential and recommended design methodology will be further documented in future papers reporting results from lateral load and buckling tests on twin-girder systems.

\section{Appendix}

Summary of the test data for $0.75,0.91$, and $1.63 \mathrm{~mm}(0.030 \mathrm{in}$, 0.036 in, 0.048 in, and 0.060 in) Thick Deck Forms (Table 2).

\section{References}

AASHTO. (2002). Standard specifications for highway bridges, 17th Ed., Washington, D.C.

AASHTO. (2004). Load and resistance factor design specification (LRFD) bridge design specifications, 3rd Ed., Washington, D.C.

Currah, R. M. (1993). "Shear strength and shear stiffness of permanent steel bridge deck forms." MS thesis, Univ. of Texas at Austin, Austin, Tex.

Davies, J. M., and Bryan, E. R. (1982). Manual of stressed skin diaphragm design, Wiley, New York.

Egilmez, O. O. (2005). "Lateral bracing of steel bridge girders by Permanent metal deck forms." Ph.D. dissertation, Univ. of Houston, Houston.

Errera, S. J., and Apparao, T. V. S. R. (1976). "Design of I-shaped beams with diaphragm bracing." J. Struct. Div., 102(4), 769-781.

Galambos, T. V., ed. (1998). Guide to stability design criteria for metal structures, 5th Ed., Wiley, New York.

Helwig, T. A. (1994). "Lateral bracing of bridge girders by metal deck forms." Ph.D. dissertation, Univ. of Texas at Austin, Austin, Tex.

Helwig, T. A., and Frank, K. H. (1999). "Stiffness requirements for diaphragm bracing of beam." J. Struct. Eng., 125(11), 1249-1256.

Luttrell, L. D. (1981). Steel Deck Institute diaphragm design manual, 1st Ed., St. Louis, Mo.

Luttrell, L. D. (2004). Steel Deck Institute diaphragm design manual, 3rd Ed.

Soderberg, E. (1994). "Strength and stiffness of stay-in-place metal deck form systems." MS thesis, Univ. of Texas at Austin, Tex.

Texas Dept. of Transportation (TxDOT). (2004). Permanent metal deck form standards, Bridge Division.

Winter, G. (1958). "Lateral bracing of columns and beams." J. Struct. Div., 84(2), 1-22. 